\title{
PRINSIP NEW AND NOVELTY DALAM PERLINDUNGAN PATEN DI INDONESIA
}

\author{
Ni Kadek Wedayanti Ari Suputri, Fakultas Hukum Universitas Udayana, \\ e-mail: wedayanti 13@gmail.com \\ Ida Ayu Sukihana, Fakultas Hukum Universitas Udayana, \\ e-mail : ayu_sukihana@unud.ac.id
}

doi: https://doi.org/10.24843/KS.2020.v08.i08.p11

\begin{abstract}
ABSTRAK
Studi ini bertujuan untuk mengkaji persyaratan dalam permohonan perlindungan paten dan menganalisis pernerapan prinsip new and novelty dalam perlindungan paten. Metode penelitian yang digunakan dalam studi ini adalah metode penelitian hukum normatif dengan pendekatan perundangundangan dan pendekatan konseptual. Dalam menunjang studi ini digunakan bahan hukum primer berupa peraturan perundang-undangan yaitu Undang-Undang No. 13 Tahun 2016 Tentang Paten dan bahan hukum sekunder yaitu buku-buku dan literatur tentang paten yang menunjang studi ini. Pengumpulan bahan hukum menggunakan teknik studi kepustakaan. Setelah bahan hukum terkumpul maka perlu dianalisa bahan-bahan hukum tersebut untuk kepentingan studi ini dengan menggunakan teknik analisis deskriptif. Hasil dari studi ini menjelaskan bahwa (1) Persyaratan dalam Permohonan Perlindungan Paten termuat dalam Pasal 24 sampai Pasal 29 Undang-Undang No. 13 Tahun 2016 Tentang Paten; dan (2) Penerapan prinsip new and novelty merupakan persyaratan substantive dalam permohonan perlindungan paten sehingga suatu invensi harus memenuhi prinsip tersebut agar memperoleh perlindungan Paten.
\end{abstract}

Kata Kunci : New, Novelty, Paten

\begin{abstract}
This study aims to examine the requirements in applying for patent protection and analyze the application of new and novelty principles in patent protection. The research method used in this study is a normative legal research method with a statutory and conceptual approach. In supporting this study primary legal materials are used in the form of legislation namely Law No. 13 of 2016 concerning Patents and secondary legal materials namely books and literature on patent that support this study. Collection of legal materials using literature study techniques. After the legal materials are collected it is necessary to analyze these legal materials for the benefit of this study by using descriptive analysis techniques. The results of this study explain that (1) The requirements in the Patent Protection Application are contained in Article 24 to Article 29 of Law No. 13 of 2016 concerning patents; and (2) The application of the principle of new and novelty is a substantive requirement in an application for patent protection so that an invention must meet these principles in order to obtain patent protection.
\end{abstract}

\section{Keywords: New, Novelty, Patent}

\section{Pendahuluan}

\subsection{Latar Belakang Masalah}

Menurut Carolyn Hotckis dalam “International Law for Bisnis" yang dikutip oleh Maria Alfons, bahwa "saat ini sistem hukum meletakkan kekayaan kedalam tiga kategori, pertama, sebagian besar masyarakat mengakui hak kepemilikan pribadi dalam kekayaan pribadi, yang dikenal dengan in tangible things; kedua, kekayaan dalam pengertian riil seperti tanah dan bangunan; dan ketiga, kekayaan yang 
diketahui sebagai kekayaan intelektual." Terkait dengan Kekayaan Intelektual, semua negara mengakui hak kekayaan dalam bentuk produk ide, seperti dalam bentuk hak cipta, paten, merek dan rahasia dagang, tata letak sirkuit terpadu, varietas tanaman. ${ }^{1}$

Hak Kekayaan Intelektual pada umumnya berhubungan dengan perlindungan penerapan ide dan informasi yang memiliki nilai komersial. Secara faktual, Hak Kekayaan Intelektual merupakan "satu sistem pemberian perlindungan hukum bagi karya-karya intelektual yang mencakup jangkauan yang luas, dari pengetahuan tradisional sampai program komputer dan Internet di era bisnis digital saat ini. Hak Kekayaan Intelektual merupakan hak untuk menikmati hasil kreativitas intelektual manusia secara ekonomis". ${ }^{2}$

Hak Kekayaan Intelektual sangat penting memperoleh perlindungan, hal ini karena hak kekayaan intelektual merupakan hak yang timbul dari kekayaan yang diciptakan oleh kreativitas dan olah pikir intelektual manusia.Manusia terlahir dengan cipta dan karsa sehingga adanya kreativitas dalam diri manusia yang mampu melahirkan karya-karya intelektu. ${ }^{3}$ Karya-karya intelektual tersebut memiliki nilai ekonomi dan bermanfaat bagi kehidupan manusia dalam meningkatkan kekayaan. Indonesia pada zaman dahulu tidak mengenal adanya perlindungan terkait hak kekayaan intelektual. Perlindungan hak kekayaan intelektual berakar dari negara maju yang memiliki pengaturan perundang-undangan terkait hak kekayaan intelektual. Pengaturan terkait hak kekayaan intelektual disepakati melalui berbagai konvensi Internasional yaitu Berne Convention, Universal Copyright Convention (UCC), Convention Establishing the World Intellectual Property Organization (WIPO), Patent Cooperation Treaty (PCT), The Hague Agreement Concerning the International Deposit of Industrial Designs, Paris Convention, serta TRIPs-WTO Agreement.

Hak kekayaan intelektual termasuk kedalam hukum kebendaan tidak berwujud yang terdiri dari 2 bagian besar yaitu : (1) Industrial property rights atau hak kekayaan industrial berkaitan dengan invensi, atau inovasi yang berhubungan dengan kegiatan industri yang meliputi paten, merek, desain industri, rahasia dagang (trade secret atau know how), dan desain tata letak sirkuit terpadu (lay outdesign of integrated circuits); dan (2) Copyrights atau hak cipta yang memberikan perlindungan terhadap karya-karya seni, sastra dan ilmu pengetahuan, contoh : film, lukisan, novel, program computer, tarian dan sebagainya.

Paten merupakan "salah satu bagian dari hak kekayaan industrial." Pasal 1 huruf a Undang-Undang No. 13 Tahun 2016 Tentang Paten (Selanjutnya disebut UU Paten) menjelaskan bahwa Paten adalah "hak eksklusif yang diberikan oleh negara kepada inventor atas hasil invensinya di bidang teknologi untuk jangka waktu tertentu melaksanakan sendiri invensi tersebut atau memberikan persetujuan kepada pihak lain untuk melaksanakannya." Pengertian invensi termuat dalam Pasal 1 huruf b yang menjelaskan bahwa invensi adalah "ide inventor yang dituangkan ke dalam suatu kegiatan pemecahan masalah ang spesifik di bidang teknologi berupa produk atau proses, atau penyempurnaan dan pengembangan produk atau proses." Sementara

1 Alfons, Maria. "Implementasi hak kekayaan intelektual dalam perspektif negara hukum." Jurnal Legislasi Indonesia 14, no. 3 (2017): 301-311

2 Nugroho Nugroho, Sigit. "Perlindungan Hak Kekayaan Intelektual Dalam Upaya Peningkatan Pembangunan Ekonomi Di Era Pasar Bebas ASEAN." Supremasi Hukum: Jurnal Penelitian Hukum 24, no. 2 (2015): 164-178.

3 Dharmawan, Ni Ketut Supasti, dkk. Harmonisasi hukum kekayaan intelektual Indonesia. (Denpasar, Swasta Nulus, 2018), 6 
inventor adalah seorang atau beberapa orang yang secara bersama-sama melaksanakan ide yang dituangkan ke dalam kegiatan yang menghasilkan invensi.

Pasal 3 ayat 1 UU Paten mengatur bahwa "Paten yang memperoleh perlindungan paten diberikan untuk invensi yang baru, mengandung langkah inventif dan dapat diterapkan dalam industri." Invensi yang baru dalam ketentuan Pasal ini menjelaskan bahwa "sebuah invensi harus baru dan tidak pernah digunakan sebelumnya." Selain itu, dalam ketentuan Pasal 5 ayat 1 UU Paten menjelaskan Invensi dianggap baru jika pada tanggal penerimaan, invensi tersebut tidak sama dengan teknologi yang diungkapkan sebelumnya." Ketentuan pasal 3 ayat 1 dan pasal 5 ayat 1 merupakan "sebuah prinsip dasar dalam perlindungan Paten." Prinsip ini disebut dengan New (baru) dan Novelty (kebaruan). Namun dapat dianalisa bahwa mengenai kadar penentu sebuah invensi disebut baru dengan unsur kebaruan tersebut hanya ditentukan oleh Direktorat Jendral Hak Kekayaan Intelektual dan UU Paten tidak mengatur secara mandalam mengenai prinsip kebaruan tersebut.

Penelitian sebelumnya mengenai Prinsip New and Novelty terdapat dalam penelitian yang dilakukan oleh Agita Kresna Adiyan dengan Judul "Penerapan Prinsip Kebaruan (Novelty) Dalam Perlindungan Desain Industri di Indonesia (Studi Kasus Desain Industri Iphone 3G Apple Inc. vs. Galaxy S Samsung Electronics Co. Ltd)" yang telah terbit pada Kumupulan Jurnal Mahasiswa Fakultas Hukum, Universitas Brawijaya. Penelitian ini merujuk pada prinsip novelty dalam desain industri. Oleh karena itu dalam tulisan ini menarik untuk dikaji mengenai "Prinsip New and Novelty dalam Perlindungan Paten di Indonesia"

\subsection{Rumusan Masalah}

Berdasarkan latar belakang yang telah dipaparkan, diperoleh rumusan masalah sebagai berikut :

1. Bagaimanakah persyaratan dalam permohonan perlindungan paten ?

2. Bagaimanakah penerapan prinsip new and novelty dalam perlindungan paten?

\subsection{Tujuan Penulisan}

Studi ini bertujuan untuk mengkaji serta menganalisis persyaratan dalam permohonan perlindungan paten dan menganalisis pernerapan prinsip new and novelty dalam perlindungan paten..

\section{Metode Penelitian}

Studi ini menggunakan metode penelitian hukum normatif yang mengkaji norma hukum melalui peraturan perundang-undangan terhadap suatu permasalahan tertentu. ${ }^{4}$ enis pendekatan yang digunakan dalam studi ini ialah pendekatan perundang-undangan (statue approach) dan pendekatan konseptual (conceptual approach).Dalam menunjang studi ini digunakan bahan hukum primer berupa peraturan perundang-undangan yaitu Undang-Undang No. 13 Tahun 2016 Tentang Paten dan bahan hukum sekunder yaitu buku-buku dan literatur tentang paten yang menunjang studi ini. Pengumpulan bahan hukum menggunakan teknik studi kepustakaan.Setelah bahan hukum terkumpul maka perlu dianalisa bahan-bahan

4 Siyoto, Sandu, and Muhammad Ali Sodik. Dasar metodologi penelitian. (Yogyakarta, Literasi Media Publishing, 2015), 8. 
hukum tersebut untuk kepentingan studi ini dengan menggunakan teknik analisis deskriptif.

\section{Hasil dan Pembahasan}

\subsection{Persyaratan dalam Permohonan Perlindungan Paten}

Hak Kekayaan Intelektual memiliki sifat yang abstrak jika dibandingkan hak atas benda bergerak lainnya yakni hak kepemilikan atas tanah, kendaraan, dan lain sebagainya yang bisa dilihat serta memiliki wujud. Perlindungan terhadap Hak Kekayaan Intelektual dilakukan jika ide serta kemampuan intelektual manusia itu sudah diekspresikan serta diwujudkan berupa suatu karya atau hasil sehingga dapat dilihat, didengar, dibaca maupun digunakan secara praktis. ${ }^{5}$

Prinsip ideal perlindungan paten adalah sama dengan perlindungan kekayaan intelektual innya sepanjang kesemuanya bermaksud untuk melindungi seseorang yang menemukan hal sesuatu agar supaya buah pikiran dan pekerjaannya tidak dipergunakan begitu saja oleh orang lain dan menikmati hasilnya dengan merupakan hasil jerih payah mereka yang telah bekerja keras, berpikir dan mengeluarkan biaya untuk mendapatkannya. Jika dibandingkan antara hak cipta dengan paten, perbedaan antara keduanya adalah hukum yang mengatur perlindungannya yaitu hak cipta telah dilindungi sejak saat ciptaan itu diwujudkan sedangkan paten memerlukan proses pendaftaran ${ }^{6}$. Terdapat 2 jenis paten yaitu paten biasa dan paten sederhana. Paten biasa adalah "paten yang melalui penelitian atau pengembangan yang mendalam dengan lebih dari satu klaim." Paten sederhana adalah "paten yang tidak membutuhkan penelitian atau pengembangan yang mendalam dan hanya memuat satu klaim." Namun, secara tersirat terdapat jenis-jenis paten yang lain, yaitu paten proses dan paten produk. Paten proses adalah paten yang diberikan terhadap proses, sedangkan paten produk adalah paten yang diberikan terhadap produk.

Kepentingan hukum adalah "mengurusi hak dan kepentingan manusia, sehingga hukum memiliki otoritas tertinggi untuk menentukan kepentingan manusia yang perlu diatur dan dilindungi." Perlindungan hukum harus melihat tahapan yakni perlindungan hukum lahir dari suatu ketentuan hukum dan segala peraturan hukum yang diberikan oleh masyarakat yang pada dasarnya merupakan kesepakatan masyarakat tersebut untuk mengatur hubungan prilaku antara anggota-anggota masyarakat dan antara perseorangan dengan pemerintah yang dianggap mewakili kepentingan masyarakat. Upaya untuk mendapatkan perlindungan hukum tentunya yang diinginkan oleh manusia adalah ketertiban dan keteraturan antara nilai dasar dari hukum yakni adanya kepastian hukum, kegunaan hukum serta keadilan hukum. Perlindungan Hukum menurut C.S.T Kansil adalah "penyempitan arti dari perlindungan, dalam hal ini hanya perlindungan oleh hukum saja." Perlindungan yang diberikan oleh hukum, terkait pula dengan adanya hak dan kewajiban, dalam hal ini yang dimiliki oleh manusia sebagai subyek hukum dalam interaksinya dengan hukum manusia serta lingkungannya. Sebagai subyek hukum manusia memiliki hak

5 Kusuma, I. Gusti Agung Larassati, and I. Wayan Wiryawan. "AKIBAT HUKUM ATAS KARYA FOTOGRAFI YANG DIKOMERSIALISASIKAN TANPA IZIN DI MEDIA SOSIAL. Kertha Semaya: Journal Ilmu Hukum" 7, no. 4 (2018): 1-15.

6 Ribowo, M. B., \& Raisah, K. PERLINDUNGAN HUKUM TERHADAP PATEN SEDERHANA DALAM SISTEM HUKUM PATEN DI INDONESIA (STUDI KOMPARASI DENGAN SISTEM HUKUM PATEN DI NEGARA CHINA). NOTARIUS, 12(1), 42-60. 
dan kewajiban untuk melakukan suatu tindakan hukum. ${ }^{7}$ Untuk itu perlu perlindungan hukum terhadap Hak Kekayaan Intelektual.

Berkaitan dengan teori perlindungan hukum Hak Kekayaan Intelektual, Robert C. Sherwood sebagaimana dikutip oleh Muhammad Fahmi Rois, Kholis Roisah ${ }^{8}$ mengatakan bahwa "pelaku industri kreatif mendapatkan perlindungan melalui reward theory, recovery theory, incentive theory, risk theory, dan economic growth stimulus theory." Konsep tersebut masing-masing adalah: reward theory yaitu "pencipta mendapatkan imbalan terhadap karya intelektual sebagai pengakuan dan penghargaan atas upaya kreatifnya." Kedua, recovery theory: "berdasarkan teori ini, pencipta atau pelaku ekonomi kreatif seharusnya memperoleh kembali apa yang dikeluarkan." Ketiga, incentive theory: menyatakan bahwa "insentif sangat penting untuk memacu pelaku ekonomi kreatif semakin meningkatkan karyanya intelektualnya." Keempat, risk theory: "teori ini mengakui bahwa suatu ciptaan memiliki risiko untuk ditiru oleh orang lain. Untuk itu sudah seharusnya ciptaan memperoleh perlindungan hukum." Kelima, economic growth stimulus theory: "pertumbuhan ekonomi dapat dilihat dari kemampuan industri kreatif sebagai industri berbasis hak kekayaan intelektual dapat menciptakan lapangan usaha dan meningkatkan perekonomian sektor riil."

Perlindungan hukum atas Paten diperoleh melalui sistem pendaftaran, yaitu Sistem Konstitutif atau yang dikenal dengan sebutan first to file system. ${ }^{9}$ Menurut sistem konstitutif, "Hak atas Paten diberikan atas dasar pendaftaran yaitu proses pendaftaran dengan melalui tahapan inventor dan pemeriksaan oleh Direktorat Jendral Hak Kekayaan Intelektual."10 Sistem pendaftaran ini menitikberatkan pada tahapan permohonan dan pemeriksaan. UU Paten dalam pasal 24 ayat 4 menjelaskan bahwa "permohonan paten dapat dilakukan dengan sistem elektronik maupun non-elektronik." Penggunaan sistem elektronik (e-filing) merupakan sebuah sistem pengajuan permohonan paten menjadi sederhana, cepat, dan biaya ringan.

Pasal 25 ayat 1 UU Paten menjelaskan persyaratan permohonan Paten paling sedikit memuat: "a. tanggal, bulan, dan tahun surat Permohonan; b. nama, alamat lengkap, dan kewarganegaraan Inventor; c. nama, alamat lengkap, dan kewarganegaraan Pemohon dalam hal Pemohon adalah bukan badan hukum; d. nama dan alamat lengkap Pemohon dalam hal Pemohon adalah badan hukum; e. nama dan alamat lengkap Kuasa dalam hal Permohonan diajukan melalui kuasa; dan f. nama negara dan Tanggal Penerimaan permohonan yang pertama kali dalam hal Permohonan diajukan dengan hak prioritas."

Selain persyaratan yang sudah dijelaskan sebelumnya, para inventor yang ingin mengajukan Permohonan harus melampirkan syarat-syarat yang termuat dalam Pasal 25 ayat 2 UU Paten yaitu : “a. judul invensi; b. deskripsi tentang invensi; c. klaim atau

7 Turatmiyah, Sri, and Y. Annalisa. "Pengakuan hak-hak perempuan sebagai pekerja rumah tangga (domestic workers) sebagai bentuk perlindungan hukum menurut hukum positif Indonesia." Jurnal Dinamika Hukum 13, no. 1 (2013): 49-58

8 Rois, Muhammad Fahmi, and Kholis Roisah. "Perlindungan Hukum Kekayaan Intelektual Kerajinan Kuningan Tumang." Kanun Jurnal Ilmu Hukum 20, no. 3 (2018): 401-419.

9 Mastur, Mastur. "Perlindungan Hukum hak kekayaan intelektual Dibidang Paten." QISTIE 6, no. 1 (2012)

10 Romadhon, Riko Fajar, and M. Fathan Nautika. "DOKTRIN PATEN DALAM SENGKETA APPLE MELAWAN SAMSUNG." Jurnal Yudisial 5, no. 3 (2012): 316-330. 
beberapa klaim invensi; d. abstrak invensi; e. gambar yang disebutkan dalam deskripsi yang diperlukan untuk memperjelas invensi, jika permohonan dilampiri dengan gambar; f. surat kuasa dalam hal permohonan diajukan melalui kuasa; g. surat pernyataan kepemilikan invensi oleh inventor; $h$. surat pengalihan hak kepemilikan invensi dalam hal permohonan diajukan oleh pemohon yang bukan inventor; dan i. surat bukti penyimpanan jasad renik dalam hal permohonan terkait dengan jasad renik."

Pemeriksaan untuk membuktikan apakah suatu invensi tersebut merupakan langkah inventif atau bukan, merupakan suatu hal yang sulit di dalam praktik. Hal tersebut dikarenakan pemeriksaan suatu invensi dibuat atas dasar apa yang dikenal umum dalam bidang kreasi tertentu, serta apakah menurut anggapan sudah dikenal oleh para ahli di bidang invensi tersebut. Pasal 2 ayat (2) UU Paten menyatakan bahwa "suatu invensi mengandung langkah inventif apabila invensi tersebut dari seseorang yang mempunyai keahlian biasa dalam bidang teknik yang bersangkutan merupakan hal yang tidak dapat diduga sebelumnya (non-obviousness)."

Suatu pengecualian dalam Paten bahwa Paten tidak diberikan untuk Invensi tentang : Pertama, proses atau produk yang pengumuman dan penggunaan atau pelaksanaanya bertentangan dengan peraturan perundang-undangan yang berlaku, moralitas agama, ketertiban umum, atau kesusilaan. Kedua, metode pemeriksaan, perawatan, pengobatan dan/atau pembedahan yang diterapkan terhadap manusia dan/atau hewan. Ketiga, teori dan metode di bidang ilmu pengetahuan dan matematika; atau (i) semua mahluk hidup, kecuali jasad renik (ii) proses biologis yang esensial untuk memproduksi tanaman atau hewan, kecuali proses non-biologis atau proses microbiologis.

Jangka waktu perlindungan paten ditentukan sebagai berikut: Pertama, paten diberikan untuk jangka waktu selama 20 (dua puluh) tahun terhitung sejak Tanggal Penerimaan dan jangka waktu itu tidak dapat diperpanjang. Kedua, tanggal mulai dan berakhirnya jangka waktu Paten dicatat dan diumumkan.Ketiga, paten Sederhana (Pasal 6) diberikan untuk jangka waktu 10 (sepuluh) tahun terhitung sejak Tanggal Penerimaan dan jangka waktu itu tidak dapat diperpanjang. Subjek Paten : Pertama, yang berhak memperoleh Paten adalah Inventor atau yang menerima lebih lanjut hak Inventor yang bersangkutan. Kedua, jika suatu Invensi dihasilkan oleh beberapa orang secara bersama-sama, hak atas Invensi tersebut dimiliki secara bersama-sama oleh para Inventor yang bersangkutan. Ketiga, kecuali terbukti lain, yang dianggap sebagai Inventor adalah orang atau beberapa orang yang untuk pertama kali dinyatakan sebagai Inventor dalam permohonan.

Kedudukan serta Perlindungan Hukum Permohonan Paten. Pertama, Paten diberikan atas dasar Permohonan. Kedua, setiap permohonan hanya dapat diajukan untuk satu invensi atau beberapa Invensi yang merupakan satu kesatuan invensi. Ketiga, permohonan diajukan dengan membayar biaya kepada Direktorat Jenderal. Keempat, permohonan diajukan secara tertulis dalam bahasa Indonesia kepada Direktorat Jenderal. Penetapan Permohonan, dilakukan: Pertama, Direktorat Jenderal mengumumkan Permohonan yang telah memenuhi ketentuan yang ditetapkan. Kedua, Pengumuman dilakukan : a. Dalam hal paten, segera setelah 18 (delapan belas) bulan sejak Tanggal Penerimaan atau segera setelah 18 (delapan belas) bulan sejak tanggal prioritas apabila Permohonan diajukan dengan Hak Prioritas; atau b. Dalam hal Paten Sederhana, segera setelah 3 (tiga) bulan sejak Tanggal Penerimaan. Ketiga, Pengumuman sebagaimana dimaksud pada ayat (2) huruf a dapat diajukan lebih awal atas permintaan Pemohon dengan dikenai biaya. 
Paten diberikan atas dasar Permohonan. Setiap Permohonan hanya dapat diajukan untuk satu Invensi atau beberapa Invensi yang merupakan satu kesatuan Invensi. Permohonan diajukan dengan membayar biaya kepada Direktorat Jenderal HKI. Permohonan diajukan secara tertulis dalam bahasa Indonesia kepada Direktorat Jenderal Kekayaan Intelektual. Sertifikat Paten merupakan bukti hak atas Paten.Paten mulai berlaku pada tanggal diberikan Sertifikat Paten dan berlaku surut sejak Tanggal Penerimaan. Pemegang paten adalah penemu sebagai pemilik paten atau orang yang menerima hak tersebut dari pemilik paten atau orang lain yang menerima lebih lanjut hak dari orang tersebut di atas, yang terdaftar dalam Daftar Umum Paten. Suatu penemuan dianggap baru, jika pada saat pengajuan permintaan paten penemuan tersebut tidak sama atau tidak merupakan bagian dari penemuan terdahulu. Pemberian hak paten bersifat teritorial, yaitu, mengikat hanya dalam lokasi tertentu. ${ }^{11}$.

\subsection{Penerapan Prinsip New and Novelty Dalam Perlindungan Paten}

Prinsip New and Novelty merupakan sebuah prinsip yang utama yang harus dimiliki oleh invensi dan inventor untuk memperoleh perlindungan terhadap invensinya. New berarti baru, dan Novelty merupakan penemuan baru yang memiliki kebaruan atau syarat kebaruan ${ }^{12}$. Berdasarkan Pasal 3 ayat 1 UU Paten dijelaskan bahwa "Paten yang memperoleh perlindungan paten diberikan untuk invensi yang baru, mengandung langkah inventif dan dapat diterapkan dalam industri." Penjelasan pasal tersebut menjelaskan bahwa "sebuah invensi harus memiliki prinsip New atau baru untuk memperoleh sebuah perlindungan paten." Suatu penemuan dapat diberikan paten apabila merupakan hasil penemuan baru dalam bidang teknologi, dengan kata lain harus merupakan hal yang baru (New), penemuan itu merupakan penemuan baru yang memiliki kebaruan atau Novelty. Dengan kata lain, new and novelty merupakan syarat mutlak yang menjadid persyaratan substantif pertama dalam permohonan perlindungan Paten.

Suatu penemuan dapat dikatakan baru jika penemuan tersebut tidak diantisipasi oleh prior art. ${ }^{13}$ Prior art adalah "semua pengetahuan yang telah ada sebelum tanggal penerimaan suatu permintaan paten (filling date) atau tanggal prioritas permintaan paten yang bersangkutan, baik melalui pengungkapan tertulis atau lisan ${ }^{14}$." Suatu invensi untuk bisa mendapatkan paten, paling tidak harus memenuhi beberapa syarat subtantif sebagaimana diatur dalam Pasal 2 ayat (1) UU.No. 13 tahun 2016 yaitu; "invensi tersebut harus mengandung unsur kebaruan (novelty), bisa diterapkan dalam

11 Sumarna, Boru Dwi. "PELUANG MAHASISWA DAN DOSEN UNTUK MENGAJUKAN PERMOHONAN HAK PATEN (UU NO. 13 TAHUN 2016 TENTANG HAK PATEN)." Jurnal Hukum Replik 6, no. 1 (2018): 121-135.

12 Adiyan, Agitya Kresna. "PENERAPAN PRINSIP KEBARUAN (NOVELTY) DALAM PERLINDUNGAN DESAIN INDUSTRI DI INDONESIA (Studi Kasus Desain Industri Iphone 3G Apple Inc. v. Galaxy S Samsung Electronics Co. Ltd)." Kumpulan Jurnal Mahasiswa Fakultas Hukum 1, no. 3 (2013)

13 Rahayu, Kanti, and Eddhie Praptono. "Deregulasi Perlindungan Hak Paten di Indonesia." Pandecta: Jurnal Penelitian Ilmu Hukum (Research Law Journal) 10, no. 1 (2015): 134143

14 Purwaningsih, Endang. "PENERAPAN WORLD WIDE NOVELTY DAN FUNCTION-WAYRESULT TEST PADA PATEN." Jurnal Yudisial 5, no. 1 (2012): 84-98. 
perindustrian (industrial aplicability), mempunyai nilai langkah inventif (inventive step), dan juga memenuhi syaratsayarat formil yang diatur dalam Pasal 24 UU. No. 13 Tahun 2016 dan Pasal 4 dan 5 PP. No. 34 Tahun 1991 Tentang Tata Cara Permintaan Paten." Syarat kebaruan yang dianut Indonesia, sebagaiman diatur dalam Pasal 3 ayat (2) UU.No. 13 Tahun 2016 menyatakan bahwa "teknologi dianggap baru apabila teknologi tersebut belum pernah diumumkan di Indonesia atau di luar negeri dalam suatu tulisan, uraian lisan, atau melalui peragaan." Sistem kebaruan yang dianut dalam Pasal 3 ayat (2) UU.No. 13 Tahun 2016 adalah Sistem kebaruan yang luas (world wide novelty).

Syarat kebaruan luas (world wide novelty) yang dianut Indonesia syarat kebaruan luas yang relative yaitu "suatu penemuan tidak dianggap telah diumumkan apabila dalam jangka waktu paling lama enam bulan sebelum tanggal penerimaan: 1) invensi tersebut telah dipertunjukkan dalam suatu pameran internasional di Indonesia atau di luar negeri yang resmi atau diakui sebagai resmi atau dalam suatu pameran nasional Indonesia yang resmi atau diakui sebagai resmi. 2) invensi tersebut telah digunakan di Indonesia oleh penemunya dalam rangka percobaan dengan tujuan penelitian dan pengembangan."15 Invensi juga dianggap telah diumumkan apabila dalam jangka waktu 12 bulan sebelum penerimaan ternyata ada pihak lain yang mengumumkan dengan cara melanggar kewajiban untuk menjaga kerahasiaan invensi tersebut ${ }^{16}$.

\section{Kesimpulan}

Berdasarkan hasil dan pembahasan yang telah dipaparkan pada sub bab sebelumnya, diperoleh kesimpulan sebagai berikut : 1) Persyaratan permohonan perlindungan atas Paten termuat dalam Pasal 24 sampai Pasal 29 UU No. 13 Tahun 2016 Tentang Paten; dan 2) Penerapan Prinsip New and Novelty dalam Perlindungan Paten merupakan prinsip yang utama yang harus dimiliki oleh sebuah invensi dan inventornya karena new dan novelty merupakan persyaratan substantive pertama agar sebuah invensi memperoleh perlindungan hukum.

Pemerintah yang berwenang dalam hal ini Direktorat Jendral Hak Kekayaan Inteelektual diharapkan mengkaji kembali UU No. 13 Tahun 2016 Tentang Paten agar mengatur secara mendalam mengenai prinsip new dan novelty tersebut. Hal ini guna mengurangi kegagalan inventor yang ingin memberi perlindungan Paten terhadap invensinya karena kurang jelasnya aturan dan makna mengenai new and novelty tersebut.

\section{DAFTAR PUSTAKA}

Buku

Dharmawan, Ni Ketut Supasti, dkk, Harmonisasi hukum kekayaan intelektual Indonesia. (Denpasar, Swasta Nulus, 2018).

Siyoto, Sandu, and Muhammad Ali Sodik. Dasar metodologi penelitian. (Yogyakarta, Literasi Media Publishing, 2015).

15 Suwardi, Suwardi. "ASPEK LEGALITAS DALAM PERLINDUNGAN HUKUM PATEN DIINDONESIA." Perspektif Hukum 18, no. 1 (2019): 157-174

16 Hanoraga, Tony, and Niken Prasetyawati. "Lisensi Wajib Paten Sebagai Salah Satu Wujud Pembatasan Hak Eksklusif Paten." JURNAL SOSIAL HUMANIORA (JSH) 8, no. 2 (2015): 160180 
Jurnal

Adiyan, Agitya Kresna. "PENERAPAN PRINSIP KEBARUAN (NOVELTY) DALAM PERLINDUNGAN DESAIN INDUSTRI DI INDONESIA (Studi Kasus Desain Industri Iphone 3G Apple Inc. v. Galaxy S Samsung Electronics Co. Ltd)." Kumpulan Jurnal Mahasiswa Fakultas Hukum 1, no. 3 (2013)..

Alfons, Maria. "Implementasi hak kekayaan intelektual dalam perspektif negara hukum." Jurnal Legislasi Indonesia 14, no. 3 (2017): 301-311.

Hanoraga, Tony, and Niken Prasetyawati. "Lisensi Wajib Paten Sebagai Salah Satu Wujud Pembatasan Hak Eksklusif Paten." JURNAL SOSIAL HUMANIORA (JSH) 8, no. 2 (2015): 160-180.

Kusuma, I. Gusti Agung Larassati, and I. Wayan Wiryawan. "AKIBAT HUKUM ATAS KARYA FOTOGRAFI YANG DIKOMERSIALISASIKAN TANPA IZIN DI MEDIA SOSIAL. Kertha Semaya: Journal Ilmu Hukum" 7, no. 4 (2018): 1-15.

Mastur, Mastur. "Perlindungan Hukum hak kekayaan intelektual Dibidang Paten." QISTIE 6, no. 1 (2012).

Nugroho, Sigit. "Perlindungan Hak Kekayaan Intelektual Dalam Upaya Peningkatan Pembangunan Ekonomi Di Era Pasar Bebas ASEAN." Supremasi Hukum: Jurnal Penelitian Hukum 24, no. 2 (2015): 164-178.

Purwaningsih, Endang. "PENERAPAN WORLD WIDE NOVELTY DAN FUNCTIONWAY-RESULT TEST PADA PATEN." Jurnal Yudisial 5, no. 1 (2012): 84-98.

Rahayu, Kanti, and Eddhie Praptono. "Deregulasi Perlindungan Hak Paten di Indonesia." Pandecta: Jurnal Penelitian Ilmu Hukum (Research Law Journal) 10, no. 1 (2015): 134-143.

Ribowo, Mochammad Bambang, and Kholis Raisah. "PERLINDUNGAN HUKUM TERHADAP PATEN SEDERHANA DALAM SISTEM HUKUM PATEN DI INDONESIA (STUDI KOMPARASI DENGAN SISTEM HUKUM PATEN DI NEGARA CHINA)." NOTARIUS 12, no. 1: 42-60.

Rois, Muhammad Fahmi, and Kholis Roisah. "Perlindungan Hukum Kekayaan Intelektual Kerajinan Kuningan Tumang." Kanun Jurnal Ilmu Hukum 20, no. 3 (2018): 401-419..

Romadhon, Riko Fajar, and M. Fathan Nautika. "DOKTRIN PATEN DALAM SENGKETA APPLE MELAWAN SAMSUNG." Jurnal Yudisial 5, no. 3 (2012): 316-330..

Sumarna, Boru Dwi. "PELUANG MAHASISWA DAN DOSEN UNTUK MENGAJUKAN PERMOHONAN HAK PATEN (UU NO. 13 TAHUN 2016 TENTANG HAK PATEN)." Jurnal Hukum Replik 6, no. 1 (2018): 121-135.

Suwardi, Suwardi. "ASPEK LEGALITAS DALAM PERLINDUNGAN HUKUM PATEN DIINDONESIA." Perspektif Hukum 18, no. 1 (2019): 157-174.

Turatmiyah, Sri, and Y. Annalisa. "Pengakuan hak-hak perempuan sebagai pekerja rumah tangga (domestic workers) sebagai bentuk perlindungan hukum menurut hukum positif Indonesia." Jurnal Dinamika Hukum 13, no. 1 (2013): 4958.

Peraturan perundang-undangan

Undang-Undang Nomor 13 Tahun 2016 tentang Paten 